\title{
World Journal of
Pediatric Surgery transformation of the spleen in children: a two-case report of laparoscopic total or partial splenectomy and a literature review
}

\author{
Salahoudine Idrissa (D) , ${ }^{1}$ Pierre-Yves Rabattu, ${ }^{1}$ Eva Sole Cruz (D) , ${ }^{1,2}$ \\ Yohann Robert (1) , ${ }^{1}$ Christian Piolat ${ }^{1}$
}

To cite: Idrissa S, Rabattu P-Y, Sole Cruz E, et al. Sclerosing angiomatoid nodular transformation of the spleen in children: a two-case report of laparoscopic total or partial splenectomy and a literature review. World Jnl Ped Surgery 2020;3:e000153. doi:10.1136/ wjps-2020-000153

Received 24 May 2020 Revised 6 October 2020 Accepted 8 October 2020

Check for updates

(C) Author(s) (or their employer(s)) 2020. Re-use permitted under CC BY-NC. No commercial re-use. See rights and permissions. Published by BMJ.

${ }^{1}$ Department of Pediatric Surgery, Children's Hospital, University Hospital of Grenoble, Grenoble, France

${ }^{2}$ University of Grenoble Alpes, LADAF, Anatomical Laboratory, Grenoble University Hospital, Grenoble, France

Correspondence to Dr Salahoudine Idrissa; salawidrissa@gmail.com
Sclerosing angiomatoid nodular transformation (SANT) is a rare splenic lesion first described by Martel et al in 2004. ${ }^{1}$ As reported, SANT is a benign vascular lesion of the red pulp of the spleen, presenting under the microscope as angiomatoid nodules in a fibrosclerotic stroma. Although more than 200 cases have been reported in the English literature, ${ }^{2}$ only 8 cases have been found in children. SANT is most often suspected from imaging studies performed for another reason. Nevertheless, no signs are specific. ${ }^{3}$ This motivates surgery to remove the mass and confirm the diagnosis. The surgery could be done either by open, laparoscopic partial or total splenectomy. ${ }^{4}$ Herein, we reported two pediatric cases of SANT that were well treated by laparoscopic total and partial splenectomy.

A 14-year-old girl was referred to our pediatric surgery department for further investigations of a solid tumor of the spleen. The mass was diagnosed by a routine ultrasonography (US) performed in the pediatric endocrinology department in the context of urinary tract infection and chronic asthenia. The patient's medical and family history was unremarkable. On physical examination, she had good general condition without anorexia, fever or night sweats. Neither hepatosplenomegaly nor lymphadenopathies were found. The patient's blood tests showed anemia (hemoglobin $85 \mathrm{~g} / \mathrm{L}$ ) and increased inflammatory markers $[\mathrm{C}$ reactive protein (CRP): $18 \mathrm{mg} / \mathrm{L}$ and erythrocytes sedimentation rate (ESR): $40 \mathrm{~mm} /$ hour]. Abdominal US imaging found a calcified heterogeneous vascularized central splenic mass with a maximal diameter of $7 \mathrm{~cm}$ (figure 1A). The US finding was confirmed by an MRI which showed a splenic vascular tissular lesion that had an iso-intense signal on T2 sequence and a progressive signal enhancement of the central portion after injection (figure 1B). Two weeks prior to surgery, she was vaccinated against Streptococcus pneumoniae, Haemophilus influenzae, and Neisseria meningitidis. Laparoscopic total splenectomy was performed. The spleen was extracted without fragmentation through a suprapubic incision with the use of an endoscopic bag. On gross examination, the spleen weighed $450 \mathrm{~g}$ and measured $12 \times 9 \times 5 \mathrm{~cm}$ (figure 2). Histological examination showed a well demarcated multinodular lesion respecting the surrounding borders of the splenic parenchyma. The lesion was surrounded by a reactive fibrous tissue and was mainly composed of proliferative fusiform cells without cytonuclear or mitotic anomalies (figure 3A). Immunohistochemical staining showed that cells expressed CD31 and smooth muscle actin (figure 3B), vessels most often expressed CD34 and/ or CD31 whereas CD8 showed only rare sinuses trapped within these nodules. CD21, anaplastic lymphoma kinase (ALK) protein detection and in situ hybridization for the presence of Epstein-Barr virus-encoded small RNA were negative. These findings were matched with a SANT. The patient's postoperative course was uneventful. She was discharged home on day 5 with oral penicillin prophylaxis for 5 years. She remained free of symptoms and her blood tests returned to normal 6 months postoperatively. Abdominal ultrasound showed no recurrence of the lesion after 8 years of follow-up.

A 4-year-old boy was admitted to our pediatric surgery unit for management of a 

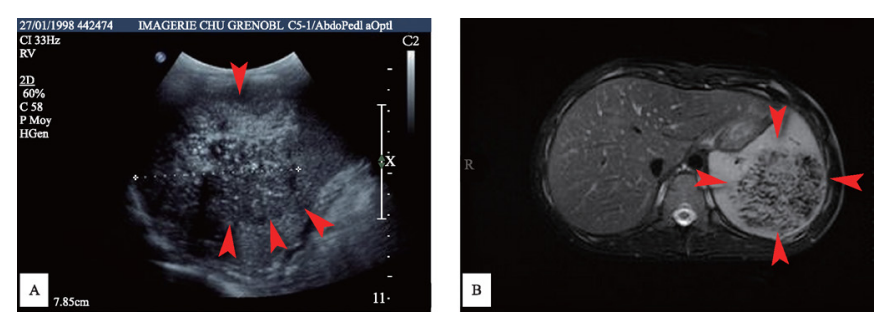

Figure 1 Imaging results of case 1. (A) Abdominal US imaging found a calcified heterogeneous vascularized central splenic mass (arrows) with a maximal diameter of $7 \mathrm{~cm}$. (B) $\mathrm{MRI}$ showed a splenic vascular tissular lesion with a maximal diameter of $7 \mathrm{~cm}$ (arrows) that had an iso-intense signal on T2 sequence and a progressive signal enhancement of the central portion after injection. US, ultrasonography.

splenic lesion. His mother reported a history of recurrent bouts of abdominal pain for a year. The patient had been hospitalized for bronchiolitis complicated with respiratory syncytial virus pneumonia at 6 months of age. His mother also reported a history of pyelonephritis at 11 months and adenoidectomy with tympanostomy at 18 months of age. He was referred to our department after an incidental finding of a heterogeneous tissular intrasplenic mass (figure 4) found on ultrasound performed by pediatricians. On physical examination, he was slightly pale without jaundice. He had a soft and non-tender abdomen with no palpable hepatosplenomegaly. A small cervical lymphadenopathy is found. The patient's white blood cell count, platelet count and hemoglobin were, respectively, $10000 / \mathrm{mm}^{3}, 342000 / \mathrm{mm}^{3}$ and $13.2 \mathrm{~g} / \mathrm{dL}$. His inflammatory markers (ESR: $11 \mathrm{~mm} /$ hour and CRP $1 \mathrm{mg} / \mathrm{L}$ ) were on normal limits. A decision was made to monitor the spleen mass with ultrasound imaging every 3 months. The mass increased from 2.5 to $3 \mathrm{~cm}$ on an US performed 3 months later. Laparoscopic partial splenectomy (LPS) was performed. Two weeks prior to surgery, she was vaccinated against $S$. pneumoniae, H. influenzae, and $N$. meningitidis. The resected spleen was extracted without fragmentation through a suprapubic incision

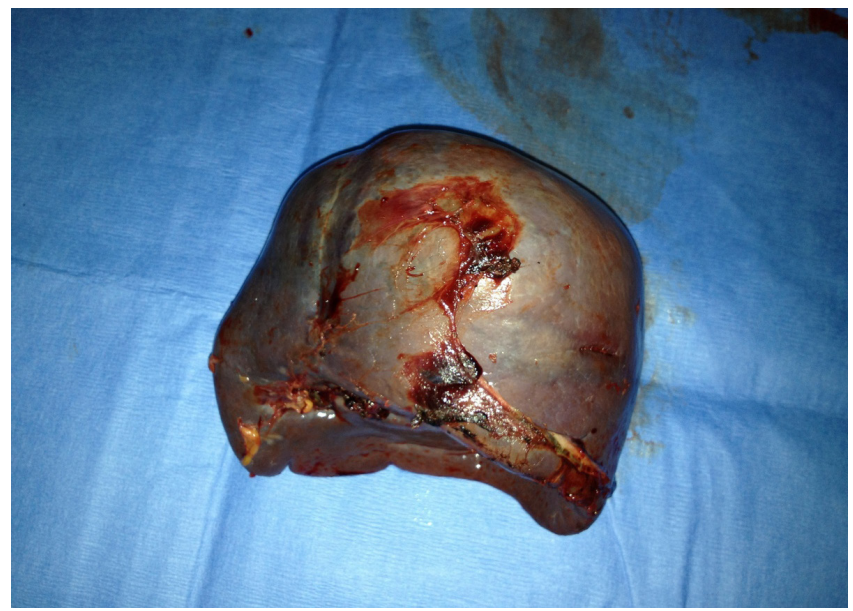

Figure 2 The gross examination of the spleen extracted without morcellation in case 1 . The spleen weighed $450 \mathrm{~g}$ and measured $12 \times 9 \times 5 \mathrm{~cm}$.

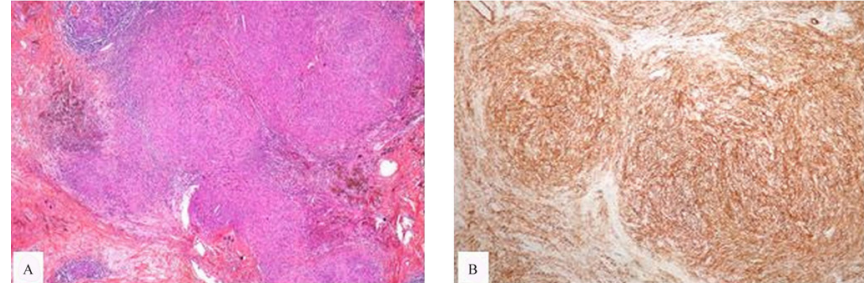

Figure 3 Histopathological results of case 1. (A) Histological $(\mathrm{HES} \times 100)$. The histological examination showed a well-demarcated multinodular lesion respecting the surrounding borders of the splenic parenchyma. The lesion was surrounded by a reactive fibrous tissue. (B) Immunohistochemical (immunohistochemistry $\times 100$ ). The immunohistochemical staining showed that cells expressed SMA. HES, hematoxylin and eosin stain; hSMA, smooth muscle actin.

with the use of an endoscopic bag. The gross examination of the resected spleen showed two fragments measuring respectively $6.5 \times 4 \times 3 \mathrm{~cm}$ and weighed $29 \mathrm{~g}$ with cystic architecture, $3 \times 3 \times 2 \mathrm{~cm}$ weighing $13 \mathrm{~g}$ with homogenous nodular aspect (figure 5). The histological analysis showed many confluent fibrotic nodules centered by vessels, associated with plasma cells, lymphocytes and macrophages (figure 6A). The immunohistochemical examination showed positive staining with CD31 and CD34 (figure 6B) by these vessels, while macrophages stained positive with CD68 and CD163. Histological and immunohistochemical findings were in favor of SANT. Postoperative course was uneventful and the patient was discharged from hospital on day three with oral penicillin prophylaxis for 5 years. An US performed 3 years postoperatively found a homogeneous spleen measuring $7 \mathrm{~cm}$ in diameter without recurrence of the mass after 6 years of follow-up.

SANT has a female predominance and mainly affects adults in the fourth to seventh decades of life. ${ }^{5}$ Although reports of SANT in the pediatric population are extremely rare, the subject seems to generate interest as some authors believe that pediatric cases may harbor a

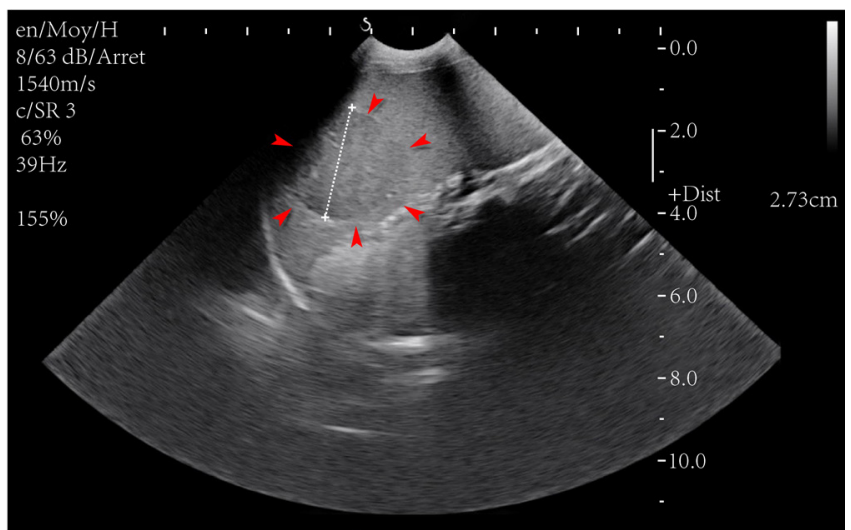

Figure 4 Imaging results of case 2. Ultrasonography showed a heterogeneous tissular intrasplenic mass (arrows), located on the lower pole of the spleen and measured $3 \mathrm{~cm}$ of maximal diameter. 


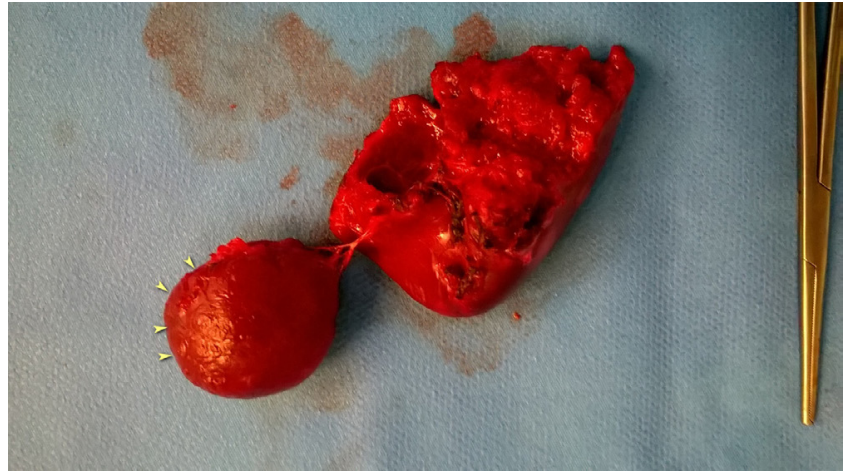

Figure 5 The gross examination of the resected spleen showed two fragments measuring respectively $6.5 \times 4 \times 3$ $\mathrm{cm}$ and weighed $29 \mathrm{~g}$ with cystic architecture, $3 \times 3 \times 2 \mathrm{~cm}$ weighing $13 \mathrm{~g}$ with homogenous nodular aspect (arrows) in case 2.

more aggressive form of the disease. ${ }^{6}$ Currently, there are no pathognomonic imaging signs. However, imaging may help to distinguish SANT from other solid splenic masses. The first imaging appearance of SANT was described by Li et $a l^{7}$ Thereafter, Karaosmanoglu et al reported the spoke-wheel pattern. ${ }^{8}$ It is a lesion that presents diffuse peripheral enhancement on the early arterial phase with progressive centripetal filling in a radiating pattern, while its center remains, respectively, hypodense and hypointense on the late phase images of CT and MRI. Despite this imaging progress, the diagnosis of SANT is based on histopathology and immunohistochemistry. ${ }^{9}$

To date, only eight cases of SANT have been reported in children. Among these cases, there were five males and three females. In contrast to adult series, herein we found a male predominance. In this study, the median age was 9 years (range, 0.2-17 years). Symptoms at presentation
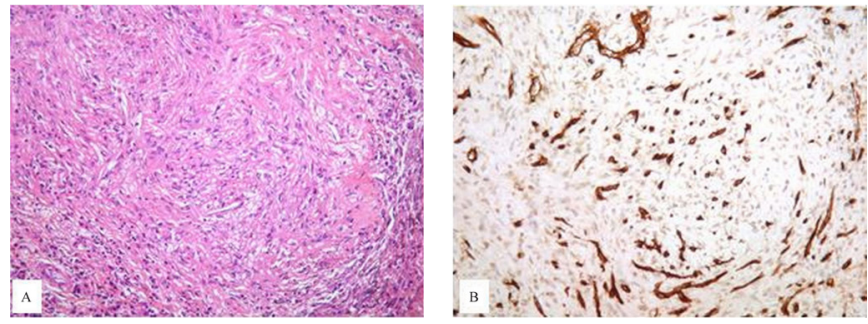

Figure 6 Histopathological results of case 2. (A) Histological $(H E S \times 200)$. The histological analysis showed many confluent fibrotic nodules centered by vessels, associated by plasma cells, lymphocytes and macrophages. (B) Immunohistochemical (immunohistochemistry $\times 400$ ). The immunohistochemical examination showed positive staining with CD31 and CD34 by these vessels, while macrophages stained positive with CD68 and CD163.

were recurrent abdominal pains, vomiting, asthenia and growth retardation. The physical examination revealed a splenomegaly, anemia, abdominal pain and cervical lymphadenopathy. However, in two patients, the diagnosis was made incidentally. Demographics, physical features, surgical treatment and follow-up of children with the SANT of the spleen were summarized in table 1. The present study reports the first child operated by LPS and advocates its safety and efficiency in children on the basis of literature review. Improvement of laparoscopic equipment and techniques have made LPS widely used in digestive surgery as well as in the treatment of focal benign splenic lesions. This has been facilitated by the understanding of splenic anatomy, especially knowledge of the intrinsic and extrinsic vascularization of the spleen.

Recently, Jin et at suggested that LPS appeared to be a technically feasible and therapeutically effective approach for SANT. Authors have reported 37 adult

Table 1 Demographics, physical features, surgical treatment and follow-up of children with the sclerosing angiomatoid nodular transformation of the spleen

\begin{tabular}{|c|c|c|c|c|c|}
\hline $\begin{array}{l}\text { Authors } \\
\text { Reference }\end{array}$ & Age (y) & Gender & Physical examination & Surgical technique & Follow-up \\
\hline Delgado et $a l^{2}$ & 4 & Male & $\begin{array}{l}\text { Recurrent vomiting and } \\
\text { anemia }\end{array}$ & Laparoscopic splenectomy & No recurrence \\
\hline Cao et $a l^{3}$ & 7 & Male & Incidental finding & Not available & No recurrence \\
\hline Bamboat et $a l^{6}$ & 17 & Male & $\begin{array}{l}\text { Intermittent abdominal pain, } \\
\text { left upper quadrant pain }\end{array}$ & Laparoscopy splenectomy & 7 mon no recurrence \\
\hline Kuybulu et al ${ }^{10}$ & 11 & Female & $\begin{array}{l}\text { Growth retardation, } \\
\text { splenomegaly }\end{array}$ & Open splenectomy & Not available \\
\hline Vyas et $a l^{11}$ & 1 & Male & Abdominal pain : left flank & Open partial splenectomy & 36 mon no recurrence \\
\hline Zhang et $\mathrm{al}^{12}$ & 3 & Male & Incidental finding & Open partial splenectomy & 20 mon no recurrence \\
\hline Agrawal et al ${ }^{13}$ & 12 & Female & Upper quadrant discomfort & Open splenectomy & 24-60 mon, no recurrence \\
\hline Pelizzo et $a^{14}$ & 0.2 & Female & $\begin{array}{l}\text { Abdominal distension and } \\
\text { rectal bleeding }\end{array}$ & Open splenectomy & Not available \\
\hline \multicolumn{6}{|l|}{ Our study } \\
\hline Case 1 & 14 & Female & Asthenia & Laparoscopy splenectomy & 96 mon, no recurrence \\
\hline Case 2 & 4 & Male & $\begin{array}{l}\text { Recurrent abdominal pains, } \\
\text { pallor, cervical adenopathy }\end{array}$ & $\begin{array}{l}\text { Laparoscopy partial } \\
\text { splenectomy }\end{array}$ & 72 mon, no recurrence \\
\hline
\end{tabular}


patients managed by open splenectomy (12 patients), laparoscopic splenectomy (12 patients), or LPS (13 patients). The authors found no difference regarding the operation time, blood loss, length of hospital stay, or postoperative complications among the three groups. Thus, current partial laparoscopy is based on the surgical anatomy of the spleen. Devascularization of a specific segment creates a demarcation line, which allows resection of the segment. ${ }^{4}$

In our study, the choice of partial or total splenectomy was based on size and/or location of the lesion. Thus, in our first clinical case, the spleen lesion was central and was measured to be $7 \mathrm{~cm}$ in diameter (that is, more than half of the spleen itself). In this circumstance, partial splenectomy was not feasible. In addition, because the etiology of this mass remains unknown, resection of the mass should respect rules of surgical oncology even though malignant spleen tumors are extremely rare in children. In the second clinical case, the lesion was located on the lower pole of the spleen and was measured to be $3 \mathrm{~cm}$ in diameter, allowing easier for LPS within an experienced surgeon. An approximately $5 \mathrm{~cm}$ suprapubic transversal incision was done to extract the spleen specimen without fragmentation and avoiding any fluid spread. In both cases, no recurrence of the lesion was reported after 8 and 6 years of follow-up, respectively. Effectively, laparoscopy splenectomy studies in children revealed no recurrence after follow-up. ${ }^{26}$

According to literature, patients treated by LPS are at low risk of serious complications, such as overwhelming postsplenectomy infection. ${ }^{4}$ Within an experienced surgeon, LPS shortens length of hospital stay, reduces medical expenses with fewer wound complications and offers better cosmetic outcomes. Among the existing literature, no serious short-term or long-term complications have been reported after LPS. Therefore, we believe that when possible, LPS should be regarded as the first-line treatment of SANT in children.

Acknowledgements We thank patients and their parents for allowing us to publish these case reports.

Contributors IS conceived the study and drafted the manuscript. RY, CES and PC Christian participated in surgery. RPY has been involved in drafting and critical revision of the manuscript. PC has revised the manuscript. All authors read and approved the final manuscript.

Funding The authors have not declared a specific grant for this research from any funding agency in the public, commercial or not-for-profit sectors.

Competing interests None declared.

Patient consent for publication Obtained.
Ethics approval Study ethics approval was obtained on 05 August 2020 (CECIC Rhône-Alpes-Auvergne, Clermont-Ferrand, IRB 5891)

Provenance and peer review Not commissioned; externally peer reviewed.

Data availability statement Data are available in a public, open access repository. Data are available on the network database (cristal net) of the Department of Pediatric Surgery, Children's Hospital, University Hospital of Grenoble.

Open access This is an open access article distributed in accordance with the Creative Commons Attribution Non Commercial (CC BY-NC 4.0) license, which permits others to distribute, remix, adapt, build upon this work non-commercially, and license their derivative works on different terms, provided the original work is properly cited, appropriate credit is given, any changes made indicated, and the use is non-commercial. See: http://creativecommons.org/licenses/by-nc/4.0/.

ORCID iDs

Salahoudine Idrissa http://orcid.org/0000-0003-1284-1870

Eva Sole Cruz http://orcid.org/0000-0003-3224-132X

Yohann Robert http://orcid.org/0000-0003-0353-8511

\section{REFERENCES}

1 Martel M, Cheuk W, Lombardi L, et al. Sclerosing angiomatoid nodular transformation (SANT): report of 25 cases of a distinctive benign splenic lesion. Am J Surg Pathol 2004;28:1268-79.

2 Delgado MA, Fleming A, El-Gohary Y, et al. Sclerosing Angiomatoid nodular transformation of the spleen in a four-year-old with anemia. J Pediatr Surg Case Rep 2018;38:53-6.

3 Cao P, Wang K, Wang C, et al. Sclerosing angiomatoid nodular transformation in the spleen: a case series study and literature review. Medicine 2019;98:e15154.

4 Jin Y, Hu H, Regmi P, et al. Treatment options for sclerosing angiomatoid nodular transformation of spleen. HPB 2020. doi:10.1016/j.hpb.2020.01.014. [Epub ahead of print: 13 Feb 2020].

5 Falk GA, Nooli NP, Morris-Stiff G, et al. Sclerosing Angiomatoid nodular transformation (SANT) of the spleen: case report and review of the literature. Int J Surg Case Rep 2012;3:492-500.

6 Bamboat ZM, Masiakos PT. Sclerosing angiomatoid nodular transformation of the spleen in an adolescent with chronic abdominal pain. J Pediatr Surg 2010;45:e13-16.

7 Li L, Fisher DA, Stanek AE. Sclerosing angiomatoid nodular transformation (SANT) of the spleen: addition of a case with focal CD68 staining and distinctive CT features. Am J Surg Pathol 2005;29:839-41.

8 Karaosmanoglu DA, Karcaaltincaba M, Akata D. Ct and MRI findings of sclerosing angiomatoid nodular transformation of the spleen: spoke wheel pattern. Korean J Radiol 2008;9 Suppl:S52-5.

9 Niu M, Liu A, Wu J, et al. Sclerosing angiomatoid nodular transformation of the accessory spleen: a case report and review of literature. Medicine 2018;97:e11099.

10 Kuybulu A, Sipahi T, Topal I, et al. Splenic angiomatoid nodular transformation in a child with increased erythrocyte sedimentation rate. Pediatr Hematol Oncol 2009;26:533-7.

11 Vyas M, Deshmukh M, Shet T, et al. Splenic angiomatoid nodular transformation in child with inflammatory pseudotumor-like areas. Indian J Pathol Microbiol 2011;54:829-31.

12 Zhang S, Yang W, Hongyan XU, et al. Sclerosing Angiomatoid nodular transformation of spleen in a 3-year-old child. Indian Pediatr 2015;52:1081-3.

13 Agrawal M, Uppin SG, Bh S, et al. Sclerosing Angiomatoid nodular transformation of the spleen: a new entity or a new name? Turk Patoloji Derg 2016;32:205-10.

14 Pelizzo G, Villanacci V, Lorenzi L, et al. Sclerosing angiomatoid nodular transformation presenting with abdominal hemorrhage: first report in infancy. Pediatr Rep 2019;11:7848. 